\title{
Bone Health Should Be an Important Concern in the Care of Patients Affected by 21 Hydroxylase Deficiency
}

\author{
Anne Bachelot, ${ }^{1,2}$ Zeina Chakhtoura, ${ }^{1,2}$ Dinane Samara-Boustani, ${ }^{3}$ Jérome Dulon,, $2^{1,2}$ \\ Philippe Touraine, ${ }^{1,2}$ and Michel Polak ${ }^{3}$
}

\author{
${ }^{1}$ AP-HP, Department of Endocrinology and Reproductive Medicine, Groupe Hospitalier Pitié-Salpétrière, \\ 47-83 boulevard de l'Hôpital, 75013 Paris Cedex 13, France \\ ${ }^{2}$ Centre de Référence des Maladies Endocriniennes Rares de la Croissance, Groupe Hospitalier Pitié-Salpétrière, \\ 47-83 boulevard de l'Hôpital, 75013 Paris Cedex 13, France \\ ${ }^{3}$ AP-HP, Department of Pediatric Endocrinology and Gynecology, Hôpital Necker-Enfants Malades, \\ 149 rue de Sèvres, 75015 Paris, France
}

Correspondence should be addressed to Philippe Touraine, philippe.touraine@psl.aphp.fr and Michel Polak, michel.polak@nck.aphp.fr

Received 6 April 2010; Accepted 8 July 2010

Academic Editor: John Fuqua

Copyright (๑) 2010 Anne Bachelot et al. This is an open access article distributed under the Creative Commons Attribution License, which permits unrestricted use, distribution, and reproduction in any medium, provided the original work is properly cited.

\begin{abstract}
Osteoporosis has been an understandable concern for children and adult patients with congenital adrenal hyperplasia (CAH) who may receive or have received supraphysiological doses of glucocorticoids. Some previous reports on bone mineral density (BMD) in adult $\mathrm{CAH}$ patients showed no significant differences in BMD between patients with CAH and controls, but others have found lower BMD in $\mathrm{CAH}$ patients. In reports documenting the BMD reduction, this outcome has been attributed to an accumulated effect of prolonged exposure to excess glucocorticoids during infancy and childhood. We recently conducted a trial to establish the role of the total cumulative glucocorticoid dose on BMD. We established for the first time that there was a negative relationship between total cumulative glucocorticoid dose and lumbar and femoral BMD. Women might benefit from the preserving effect of estrogens compared to men. BMI (Body Mass Index) also appeared to protect patients from bone loss. In light of this, physicians should bear in mind the potential consequences of glucocorticoids on bone and therefore adjust the treatment and improve clinical and biological surveillance from infancy. Furthermore, preventive measures against corticosteroid-induced osteoporosis should be discussed right from the beginning of glucocorticoid therapy.
\end{abstract}

\section{Introduction}

Congenital adrenal hyperplasia (CAH, MIM 201910) describes a group of inherited autosomal recessive disorders characterized by enzyme defects in the steroidogenic pathways that lead to the biosynthesis of cortisol, aldosterone, and androgens. Many different mutations of the CYP21 gene have been identified causing varying degrees of impairment of 21-hydroxylase activity that result in a spectrum of disease expression [1]. Most patients are compound heterozygotes, and the clinical phenotype is generally related to the less severely mutated allele and, consequently, to the residual 21 hydroxylase activity.

Indeed, CAH is classified according to symptoms and signs and to age of presentation. The clinical phenotype is typically classified as classic for the severe form, or nonclassic (NCF) for the mild or late-onset form. Classic CAH is subclassified as salt-wasting (SW) or simple-virilizing (SV) forms, reflecting the degree of aldosterone deficiency. Current treatment is intended to reduce excessive ACTH and consequent increase in androgen production by substituting for deficient cortisol synthesis and, when necessary, mineralocorticoid substitution. During childhood, the main aims of the medical treatment of CAH secondary to 21hydroxylase are to prevent salt loss and virilization, to achieve normal stature, and to undergo normal puberty [2]. Undertreatment exposes the patient to the risk of adrenal crisis and allows increased adrenal androgen production, with consequent advancement of bone age and loss of growth potential. Overtreatment, however, results in growth 
retardation, truncal obesity, and osteopaenia, through the effects of steroids on growth hormone secretion and bone metabolism. In adulthood, the aims of the medical treatment are to substitute cortisol and, when necessary, aldosterone deficiency, to ensure normal fertility, and to avoid the longterm consequences of glucocorticoid use. In such an intervention, there is a narrow therapeutic window through which the intended results can be achieved. Indeed, other states, as Cushing's syndrome and pharmacological glucocorticoid therapy, can affect peak bone mass in growing individuals and generate osteoporosis via multiple mechanisms, resulting in increased bone resorption and suppression of bone formation. Chronic glucocorticoid therapy is known to generate bone loss in many ways: a direct suppression of osteoblastic activity [3] and an inhibition of digestive calcium absorption with secondary hyperparathyroidism and increased bone resorption by osteoclasts [4]. Glucocorticoids also lead to an inhibition of intestinal calcium absorption and an increase of renal calcium excretion leading to secondary hyperparathyroidism [5].

\section{Bone Mineral Density Studies in Children and Adults with 21 Hydroxylase Deficiency: Results and Limitations}

Based on these findings, many studies have attempted to analyse bone mineralization status in patients with 21hydroxylase deficiency, with the precise goal of identifying bone demineralization (Table 1). Some studies reported no significant differences in bone mineral density (BMD) between patients and controls as measured by DXA [6-11] whereas others found lower BMD or bone mineral content in all or some subpopulations of CAH patients [12-21]. These contradictory results may be explained by heterogeneous populations and methods, as the reports differ with respect to age selections and glucocorticoid regimens. Indeed, a couple of studies included pre- and postpubertal patients who had not yet reached their final height, while others sought to compare BMD with average glucocorticoid dose, at the time of the study.

The age of the patients is an important confounding factor in the study of BMD in CAH patients. Only four studies have evaluated BMD in prepubertal and in adolescent patients with the salt-wasting form of CAH $[7,14,15,21]$. Gussinyé et al. studied 16 children, 1.5 to 8.3 years old, 17 young adults, 17 to 28 years old, and a control group [7]. The average doses of hydrocortisone $\left(\mathrm{mg} / \mathrm{m}^{2}\right.$ body surface/day) received from diagnosis in the neonatal period to BMD evaluation were $21.2 \pm 2.2$ and $22.3 \pm 2.6$, respectively. Mean BMD Z score values did not show statistically significant differences with age- and sex-matched controls. Nevertheless, 4 of these children have BMD less than -1 SD. Cameron et al. concluded also that replacement therapy with glucocorticoid and mineralocorticoid hormones were not deleterious in terms of general bone mineralization in $21 \mathrm{CAH}$ patients (aged 8-32 yr) [14]. Paganini et al. showed on $50 \mathrm{CAH}$ patients (23 males, 27 females), aged 1-28 years, that an impairment in bone growth and mineralization may
TABLE 1: Summary of literature involving adult bone mineral density studies in $\mathrm{CAH}$ patients.

\begin{tabular}{|c|c|c|c|}
\hline References & $\begin{array}{c}\text { Number of } \\
\text { patients } \\
\text { (male/female) }\end{array}$ & $\begin{array}{l}\text { Age } \\
\text { (yrs) }\end{array}$ & Results on BMD \\
\hline Guo et al. [6] & $6 / 5$ & $19-65$ & Normal \\
\hline Gussinyé et al. [7] & $23 / 10$ & $1-28$ & Normal \\
\hline Mora et al. [8] & $11 / 19$ & $17 \pm 2$ & Normal \\
\hline $\begin{array}{l}\text { Stikkelbroeck et al. } \\
{[9]}\end{array}$ & $15 / 15$ & $17-25$ & Normal \\
\hline $\begin{array}{l}\text { Girgis and Winter } \\
{[10]}\end{array}$ & $12 / 16$ & $4.9-22$ & Normal \\
\hline $\begin{array}{l}\text { Christiansen et al. } \\
{[11]}\end{array}$ & $10 / 8$ & $18-33$ & Normal \\
\hline $\begin{array}{l}\text { Jaaskelainen and } \\
\text { Voutilainen [12] }\end{array}$ & $16 / 16$ & $16-52$ & Decreased \\
\hline $\begin{array}{l}\text { Hagenfeldt et al. } \\
{[13]}\end{array}$ & $0 / 13$ & $20-29$ & $\begin{array}{l}\text { Normal total BMD, } \\
\text { reduced spine BMD }\end{array}$ \\
\hline Cameron et al. [14] & $13 / 8$ & $8-32$ & $\begin{array}{l}\text { Normal in women } \\
\text { Decreased in men }\end{array}$ \\
\hline Paganini et al. [15] & $23 / 27$ & $1-28$ & Decreased \\
\hline $\begin{array}{l}\text { De Almeida Freire } \\
\text { et al. [16] }\end{array}$ & $17 / 28$ & $5-16$ & Decreased \\
\hline King et al. [17] & $0 / 26$ & $21-71$ & Decreased \\
\hline $\begin{array}{l}\text { Sciannamblo et al. } \\
{[18]}\end{array}$ & $15 / 15$ & $16-30$ & Decreased \\
\hline Bachelot et al. [19] & $9 / 36$ & $18-47$ & Decreased \\
\hline Falhammar [20] & $0 / 61$ & $18-63$ & Decreased \\
\hline Zimmermann [21] & $10 / 18$ & $5-39$ & Decreased \\
\hline
\end{tabular}

be found in young adults but not in children affected by the classical form [15]. Nevertheless, Zimmermann et al. [21] found reduced Z-score ( $\leq-1 \mathrm{SD}$ ) in $60.8 \%$ of the patients, with a percentage of $61.5 \%$ in the SW form (8/13 patients, age 5 to 17 years), and $60 \%$ in the SV form (9/15 patients, age 5.1 to 39 years). Conversely, only four studies included patients older than 50 years $[6,12,17,20]$, among which two found $\mathrm{BMD}$ alteration in $\mathrm{CAH}$ patients, that tends to be correlated with hydrocortisone dose.

DXA measurements of BMD depict areal bone density, and bone thickness is not considered. This can lead to an underestimate of BMD in small and an overestimate in large bones. A recent study has calculated BMAD $\left(\mathrm{g} / \mathrm{cm}^{3}\right)$ with formulas reported to reduce the confounding effect of bone size [20]. Even with this approach, bone density was significantly reduced in their patients at all measured sites, indicating that the differences found were real and not only due to measurement bias. This is also supported by the finding in this study that the patients and controls with normal height $(160-169 \mathrm{~cm})$ had the same differences in BMD, as was found in the entire study population [20]. Still, in very short individuals, an overestimation of osteopenia/osteoporosis may occur with conventional DXA measurements. However, DXA remains a useful tool for followup in the management of individual patients. Of interest, 
short stature by itself observed in some $\mathrm{CAH}$ patients might also be a risk factor for fractures, as small bones may be less resistant to mechanic restraints. Conversely, overweightness, obesity, and hyperandrogenism seem to be protective on BMD [19].

In studies showing alteration of BMD, Z-score, or Tscore, it has been showed to be less than $-2,5 \mathrm{SD}$ in $0 \%$ to $18 \%$ of the $\mathrm{CAH}$ patients and between $-2,5$ and $-1,0 \mathrm{SD}$ in $13 \%$ to $52 \%$ of the patients $[12,16,17$, 19]. This low BMD might be explained by glucocorticoid overtreatment itself or by suppression of androgen levels due to glucocorticoid overtreatment, and/or by premature puberty and hypogonadism induced by undertreatment or some antiandrogen treatment. However, few studies have extensively studied the link between BMD alteration and glucocorticoid dose $[12-14,17,19,21]$, as it is possible that androgen deficiency per se may be of importance for the development of low BMD, in addition to the direct catabolic effects of glucocorticoids on bone. This may be especially important in postmenopausal women.

In reports documenting the BMD reduction, this outcome has been attributed to an accumulated effect of prolonged exposure to excess glucocorticoids during infancy and childhood. The role of each of these factors has been evaluated in a number of studies published over the last decade, often with conflicting results. Most studies are retrospective, include mixed populations (children and young adults), have a small sample size, and are unable to precisely assess the effect of cumulative glucocorticoids doses. For example, Jaaskelainen and Voutilainen [12] chose a current and mean long-term glucocorticoid dose, Hagenfeldt et al. [13], an index of accumulated postmenarchal glucocorticoid medication, Sciannamblo et al. [18], the median of the last seven years of treatment, and Stikkelbroeck et al. [9], a cumulative dose which was calculated exactly over $0.5,2$, and $5 \mathrm{yr}$ preceding the investigation. Thus, some authors do not find a correlation of BMD with the present glucocorticoid dose [18], with the cumulative dose calculated for the last 2 years [6], or for the last 7 years [18], with the duration of treatment [6], or with the age of treatment start [6].

\section{Bone Mineral Density in Young Adults with 21 Hydroxylase Deficiency, in Relation to Cumulative Dose of Glucocorticoid from the Start of the Treatment}

To resolve this issue, we hypothesized that there could be a negative role of the total cumulative glucocorticoid (TCG) dose on BMD. We therefore collected the data of the daily dose of glucocorticoid received from the time of diagnosis in early infancy up to the time of inclusion in our study [22]. We considered adult patients $>16$ years old with classical CAH and nonclassical CAH that had been revealed by precocious puberty, and who had been continuously monitored and treated since childhood. Thirty eight adult patients suffering from $\mathrm{CAH}$ due to 21-hydroxylase deficiency and treated since early infancy in pediatric centers were included in our study. Twenty-four of them (63.2\%) have the saltwasting form (SW) (14 women, 10 men), 5 the simple virilizing form (SV) (13.1\%, women only in this group), and 9 the nonclassical form revealed by precocious puberty (23.7\%, women only in this group). They had all been on glucocorticoid treatment since diagnosis in infancy and 23 of them $(60.5 \%)$ were also receiving mineralocorticoid $(9 \alpha-$ fludrocortisone) during the study. The mean current dose in growth retarding hydrocortisone equivalents $(1 \mathrm{mg}$ of dexamethasone $=16 \mathrm{mg}$ of prednisone $=80 \mathrm{mg}$ of hydrocortisone) was $16.9 \pm 5.5 \mathrm{mg} / \mathrm{m}^{2} / \mathrm{d}$. Mean daily dose over a year could be distinguished in three periods: salt-wasters were treated with $23.8 \pm 8.8 \mathrm{mg} / \mathrm{m}^{2} / \mathrm{d}$ the first two years of life, patients with classical (SW and SV) and nonclassical forms had, respectively, $18.2 \pm 4.8$ and $12.7 \pm 4.1 \mathrm{mg} / \mathrm{m}^{2} / \mathrm{d}$ during childhood $(P<.001)$, and $20.4 \pm 6.4$ and $13.8 \pm 3.0 \mathrm{mg} / \mathrm{m}^{2} / \mathrm{d}$ during puberty $(P=.01)$. We found a negative effect of TCG on lumbar and femoral T-scores (Figure 1). Moreover, we demonstrated the same negative effect with TAG, which represented the average daily dose of glucocorticoids that patients received over their entire therapy life-period. In fact, $44.7 \%$ of the participants had bone demineralization according to WHO criteria, which is superior to a Gaussian repartition, in which $16 \%$ of the general population is under $-1 \mathrm{SD}$. These results are reinforced by the fact that patients do not always take their therapy as prescribed, notably during childhood and adolescence; in other words real glucocorticoid intakes may be sometimes lower than those written in files. Our results are reinforced by Van Staa's et al. meta-analysis which underlined a strong correlation between cumulative dose and loss of BMD, mean daily dose, and risk of fracture independently of underlying disease requiring corticotherapy, age, and gender [23]. A recent study [21] confirmed our results, showing a negative correlation between mean and cumulative glucocorticoid dose and treatment duration with BMD.

We found fairly normal pubertal development in boys $(11.6 \pm 1.6$ years $)$ and girls $(10.3 \pm 1.8$ years $)$ and a mean age of menarche around $13.6 \pm 1.6$ years, which had also been reported by Hughes and Read [24] and Bonfig et al. [25]. We noted low final height compared to target height, consistent with former publications [26-28], while onsetpubertal height was normal. Height gain was also reported as poor during pubertal years in studies conducted by Stikkelbroeck et al. [29] and Van der Kamp et al. [30].

\section{Bone Mineral Density in Relation to Puberty, Hormonal Status, Glucocorticoid Treatment, and Height}

This underlines the fact that the impact of glucocorticoid/androgen balance is more important than altered puberty development in this population. Firstly, hyperandrogenism during infancy due to undertreatment leads to growth velocity acceleration and a premature closure of epiphysial plates [14]. Conversely, overtreated children suffer from growth retardation $[10,31]$. One may wonder whether peak bone mass acquired during puberty might be 


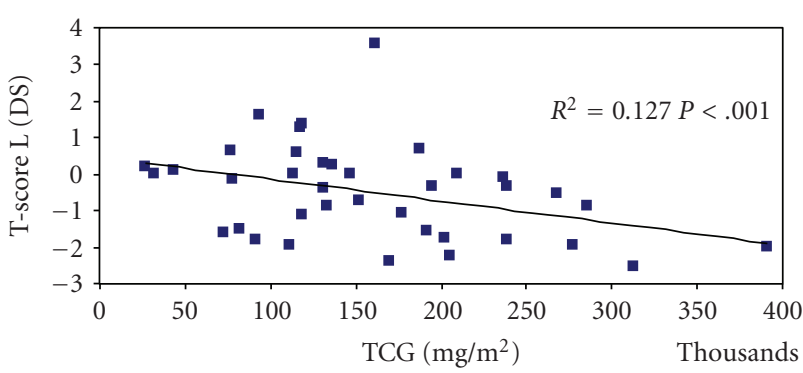

(a) TCG and lumbar T-score

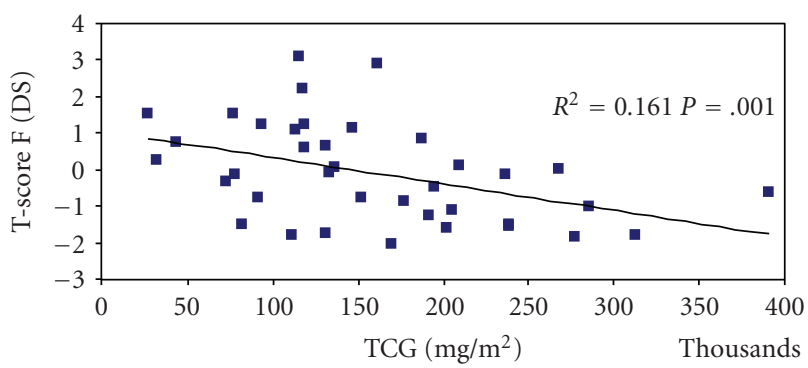

(b) TCG and femoral T-score

Figure 1: T-score regression lines explained by total cumulative glucocorticoid dose.

affected by this therapy as total pubertal growth diminishes. Indeed, we underlined that BMD was mostly affected by the glucocorticoid therapy during puberty. This corroborates Gussinye's work in which BMD values of adolescent and young adult CAH patients were significantly lower than those of the age- and sex-matched controls whereas it did not differ between prepubertal patients and controls [7]. Secondly, glucocorticoids may lead to osteoporosis [32], while androgens are known to increase bone formation markers [33, 34]. Many studies have pointed out that normal endogenous cortisol production is around $7 \mathrm{mg} / \mathrm{m}^{2} / \mathrm{d}$ in healthy people $[35,36]$ whereas clinicians advocate 10 to $15 \mathrm{mg} / \mathrm{m}^{2} / \mathrm{d}$ of exogenous therapy [37], which can bring on corticosteroid side effects in bones and result in subnormal androgen levels. In light of this, nonclassical $\mathrm{CAH}$ had better BMD than classical CAH groups, and their TAG were lower. Similarly with the literature, no correlation was found between BMD and hormonal parameters, probably because hormonal concentrations reflect a punctual measurement, while the BMD values are the integrated result of a long-term process.

\section{Sexual Dimorphism for the Impact of Demineralization in Patients with 21 Hydroxylase Deficiency}

We observed a large discrepancy between lumbar and femoral T-scores between women and men in this study. Authors of published papers explained that estrogens have a more protective action for bone mineralization than androgen [33,38], which could contribute to this result, all the more since the majority of women took exogenous estrogens. In addition, it appears that adult males with CAH face a dual problem: (1) adrenal steroid overproduction, especially androgen and progesterone which are less protective on BMD than testosterone, might interfere with FSH and $\mathrm{LH}$ production, resulting in gonadotropin deficiency and consequent small testicular size and lower testosterone levels $[39,40]$, and (2) adrenal rests can interfere directly with the endocrine function of normal testicular tissue in a mechanical way or by local steroid production. Furthermore, supraphysiological doses of glucocorticoids can inhibit gonadotrophic axis and also deprive bone of the protective role of testosterone. We showed that BMD in women taking exogenous estrogens were similar compared with those who were not under estrogen therapy. Nevertheless, we did not distinguish between different hormonal treatments, their duration, or the periods over which they were administered. Finally, our population was fairly young at $24.6 \pm 5.9$ years, the oldest patient being 39. It is recognized that men and premenopausal women may suffer from glucocorticoidinduced osteoporosis [41, 42], and postmenopausal women also have a high risk of fracture during corticosteroid treatment [43].

\section{Fractures in Patients with 21 Hydroxylase Deficiency}

Osteoporosis is a strong risk factor for fractures, but only one study has evaluated fractures in $\mathrm{CAH}$ patients [20]. This study included 61 women, aged 18-63 yr, 27 with salt wasting, 28 with simple virilizing, and 6 with nonclassical 21-hydroxylase deficiency. A total of 61 age-matched women were controls. Results indicated a higher frequency of fractures in women with $\mathrm{CAH}$. When only osteoporotic fractures (vertebrae, wrist, and hip) were considered, the difference almost reached significance $(P=.058)$. This is of importance for $\mathrm{CAH}$ patients, even if this finding has to be confirmed in larger studies, which should evaluated differences in lifestyle between patients and controls, as the trauma leading to fractures was not ascertained. This is in accordance with a study showing increased risk of fractures in patients receiving glucocorticoid therapy, even with low dose [44]. We may then suppose that aging patients with $\mathrm{CAH}$ are at risk of fracture; therefore, preventive methods might be introduced, including physical activity and diet-recommendations and vitamin D supplementation if necessary [45].

\section{Bone Turnover Markers in 21 Hydroxylase Deficiency}

Biochemical markers of bone turnover have also been partially evaluated in patients with CAH $[6,10,15,18,20]$, and literature data are inconclusive. Bone turnover was found to be lower in patients with CAH than in controls, and osteocalcin levels correlated positively with growth velocity and negatively with $\mathrm{BMD}[6,10]$. Another recent study showed higher bone-specific alkaline phosphatase (ALP) and serum $\beta$-C-telopeptide of type I collagen (CTX) concentrations in $\mathrm{CAH}$ patients compared with control subjects, 
but this did not correlate with the actual glucocorticoid dose or the mean dose used during the previous 7 yrs [18]. The bone resorption marker CTX was recently reevaluated [20]. It was reduced in the older group of patients both compared with controls and younger patients. This was not in accordance with the findings of Sciannamblo et al. [18] and of Zimmermann et al. [21] that observed elevated CTX concentrations in young individuals, some still growing. The authors concluded that the CAH patients treated for many years had predominantly low bone formation but also unexplained low bone resorption [46]. Regarding the parameters of bone mineralization, a few patients of the study by Falhammar et al. exhibited PTH levels above the upper level of the reference range concomitant with low normal calcium concentrations, and they were all osteopenic [20]. This can be interpreted as secondary hyperparathyroidism, likely attributable for the authors to glucocorticoid therapy. However, the 25-hydroxyvitamin D levels were not assessed in this study.

Finally, possible role of GH has been assessed. Indeed, glucocorticoid administration may affect the growth axis in CAH in several ways. While CAH patients have normal responses to provocative $\mathrm{GH}$ stimulation testing, it has been suggested that the pattern of GH release changes with the administration of glucocorticoids [47]. However, normal IGF-I levels are reported in the majority of studies [30]. Noteworthy in Falhammar et al. study, CAH patients had higher IGF-I SDS compared with controls and the authors interpreted this phenomenon as a state of IGF-I resistance induced by glucocorticoids, and speculate that this could be a explanation for growth retardation in children on glucocorticoids.

\section{Conclusions}

Despite these conflicting results in the literature, and because some studies showed that young adult patients with the classical form of $\mathrm{CAH}$ have decreased bone density values compared with healthy controls and that this may put them at risk of developing osteoporosis early in life, CAH patients should be considered at risk for osteoporosis and fractures and physicians have to systematically check BMD in $\mathrm{CAH}$ adult patients. Furthermore, even if no interventional therapeutic study exist in $\mathrm{CAH}$ patients, preventive measures against corticosteroid-induced osteoporosis should be discussed right from the beginning of glucocorticoid therapy. Osteoporosis prophylaxis such as physical activities and calcium and vitamin D supplementation should be implemented. Therefore, Vitamin D status should systematically be determined in $\mathrm{CAH}$ patients and calcium and vitamin $\mathrm{D}$ supplementation recommended in patients with vitamin $\mathrm{D}$ deficiency and in those receiving high dose of steroids. The frequency of such measures during adulthood remains unresolved, and probably depends on the initial result of the BMD. The results obtained in adults are an incentive to follow bone mineral density in children, using the right normative data and expression of the results as $\mathrm{Z}$ score. Adequate calcium and vitamin $\mathrm{D}$ intake, in relation to the age of the child, should also be given. Finally, in accordance with the literature, optimizing the doses of glucocorticoids should always be the primary option in $\mathrm{CAH}$ patients.

\section{Acknowledgments}

Our studies were partially supported by a three-years grant from "Association Surrénales," France, http://asso.orpha.net/ AGS/cgi-bin/lassociation.

\section{References}

[1] P. C. White and P. W. Speiser, "Congenital adrenal hyperplasia due to 21-hydroxylase deficiency," Endocrine Reviews, vol. 21, no. 3, pp. 245-291, 2000.

[2] D. P. Merke and S. R. Bornstein, "Congenital adrenal hyperplasia,” The Lancet, vol. 365, no. 9477, pp. 2125-2136, 2005.

[3] L. G. Raisz and B. E. Kream, "Regulation of bone formation. I," The New England Journal of Medicine, vol. 309, no. 1, pp. 29-35, 1983.

[4] T. J. Hahn, L. R. Halstead, and D. T. Baran, "Effects of short term glucocorticoid administration on intestinal calcium absorption and circulating vitamin D metabolite concentrations in man," Journal of Clinical Endocrinology and Metabolism, vol. 52, no. 1, pp. 111-115, 1981.

[5] K. K. Berris, A. L. Repp, and M. Kleerekoper, "Glucocorticoidinduced osteoporosis," Current Opinion in Endocrinology, Diabetes and Obesity, vol. 14, no. 6, pp. 446-450, 2007.

[6] C.-Y. Guo, A. P. Weetman, and R. Eastell, "Bone turnover and bone mineral density in patients with congenital adrenal hyperplasia," Clinical Endocrinology, vol. 45, no. 5, pp. 535541, 1996.

[7] M. Gussinyé, A. Carrascosa, N. Potau et al., "Bone mineral density in prepubertal and in adolescent and young adult patients with the salt-wasting form of congenital adrenal hyperplasia," Pediatrics, vol. 100, no. 4, pp. 671-674, 1997.

[8] S. Mora, F. Saggion, G. Russo et al., "Bone density in young patients with congenital adrenal hyperplasia," Bone, vol. 18, no. 4, pp. 337-340, 1996.

[9] N. M. M. L. Stikkelbroeck, W. J. G. Oyen, G.-J. Van Der Wilt, A. R. M. M. Hermus, and B. J. Otten, "Normal bone mineral density and lean body mass, but increased fat mass, in young adult patients with congenital adrenal hyperplasia," Journal of Clinical Endocrinology and Metabolism, vol. 88, no. 3, pp. 1036-1042, 2003.

[10] R. Girgis and J. S. D. Winter, "The effects of glucocorticoid replacement therapy on growth, bone mineral density, and bone turnover markers in children with congenital adrenal hyperplasia," Journal of Clinical Endocrinology and Metabolism, vol. 82, no. 12, pp. 3926-3929, 1997.

[11] P. Christiansen, C. Mølgaard, and J. Müller, "Normal bone mineral content in young adults with congenital adrenal hyperplasia due to 21-hydroxylase deficiency," Hormone Research, vol. 61, no. 3, pp. 133-136, 2004.

[12] J. Jaaskelainen and R. Voutilainen, "Bone mineral density in relation to glucocorticoid substitution therapy in adult patients with 21-hydroxylase deficiency," Clinical Endocrinology, vol. 45, no. 6, pp. 707-713, 1996.

[13] K. Hagenfeldt, E. M. Ritzen, H. Ringertz, J. Helleday, and K. Carlstrom, "Bone mass and body composition of adult women with congenital virilizing 21-hydroxylase deficiency 
after glucocorticoid treatment since infancy," European Journal of Endocrinology, vol. 143, no. 5, pp. 667-671, 2000.

[14] F. J. Cameron, B. Kaymakci, E. A. Byrt, P. R. Ebeling, G. L. Warne, and J. D. Wark, "Bone mineral density and body composition in congenital adrenal hyperplasia," Journal of Clinical Endocrinology and Metabolism, vol. 80, no. 7, pp. 2238-2243, 1995.

[15] C. Paganini, G. Radetti, C. Livieri, V. Braga, D. Migliavacca, and S. Adami, "Height, bone mineral density and bone markers in congenital adrenal hyperplasia," Hormone Research, vol. 54, no. 4, pp. 164-168, 2000.

[16] P. O. De Almeida Freire, S. H. Valente De Lemos-Marini, A. Trevas Maciel-Guerra et al., "Classical congenital adrenal hyperplasia due to 21-hydroxylase deficiency: a cross-sectional study of factors involved in bone mineral density," Journal of Bone and Mineral Metabolism, vol. 21, no. 6, pp. 396-401, 2003.

[17] J. A. King, A. B. Wisniewski, B. J. Bankowski, K. A. Carson, H. A. Zacur, and C. J. Migeon, "Long-term corticosteroid replacement and bone mineral density in adult women with classical congenital adrenal hyperplasia," Journal of Clinical Endocrinology and Metabolism, vol. 91, no. 3, pp. 865-869, 2006.

[18] M. Sciannamblo, G. Russo, D. Cuccato, G. Chiumello, and S. Mora, "Reduced bone mineral density and increased bone metabolism rate in young adult patients with 21-hydroxylase deficiency," Journal of Clinical Endocrinology and Metabolism, vol. 91, no. 11, pp. 4453-4458, 2006.

[19] A. Bachelot, G. Plu-Bureau, E. Thibaud et al., "Long-term outcome of patients with congenital adrenal hyperplasia due to 21-hydroxylase deficiency," Hormone Research, vol. 67, no. 6, pp. 268-276, 2007.

[20] H. Falhammar, H. Filipsson, G. Holmdahl et al., "Fractures and bone mineral density in adult women with 21-hydroxylase deficiency," Journal of Clinical Endocrinology and Metabolism, vol. 92, no. 12, pp. 4643-4649, 2007.

[21] A. Zimmermann, P. G. Sido, E. Schulze et al., "Bone mineral density and bone turnover in Romanian children and young adults with classical 21-hydroxylase deficiency are influenced by glucocorticoid replacement therapy," Clinical Endocrinology, vol. 71, no. 4, pp. 477-484, 2009.

[22] Z. Chakhtoura, A. Bachelot, D. Samara-Boustani et al., "Impact of total cumulative glucocorticoid dose on bone mineral density in patients with 21-hydroxylase deficiency," European Journal of Endocrinology, vol. 158, no. 6, pp. 879887, 2008.

[23] T. P. Van Staa, H. G. M. Leufkens, and C. Cooper, "The epidemiology of corticosteroid-induced osteoporosis: a metaanalysis," Osteoporosis International, vol. 13, no. 10, pp. 777787, 2002.

[24] I. A. Hughes and G. F. Read, "Menarche and subsequent ovarian function in girls with congenital adrenal hyperplasia," Hormone Research, vol. 16, no. 2, pp. 100-106, 1982.

[25] W. Bonfig, S. Bechtold, H. Schmidt, D. Knorr, and H. P. Schwarz, "Reduced final height outcome in congenital adrenal hyperplasia under prednisone treatment: deceleration of growth velocity during puberty," Journal of Clinical Endocrinology and Metabolism, vol. 92, no. 5, pp. 1635-1639, 2007.

[26] G. Pinto, V. Tardy, C. Trivin et al., "Follow-up of 68 children with congenital adrenal hyperplasia due to 21-hydroxylase deficiency: relevance of genotype for management," Journal of Clinical Endocrinology and Metabolism, vol. 88, no. 6, pp. 2624-2633, 2003.
[27] E. A. Eugster, L. A. DiMeglio, J. C. Wright, G. R. Freidenberg, R. Seshadri, and O. H. Pescovitz, "Height outcome in congenital adrenal hyperplasia caused by 21-hydroxylase deficiency: a meta-analysis," Journal of Pediatrics, vol. 138, no. 1, pp. 26-32, 2001.

[28] A. Balsamo, A. Cicognani, L. Baldazzi et al., "CYP21 genotype, adult height, and pubertal development in 55 patients treated for 21-hydroxylase deficiency," Journal of Clinical Endocrinology and Metabolism, vol. 88, no. 12, pp. 5680-5688, 2003.

[29] N. M. M. L. Stikkelbroeck, B. A. E. Van't Hof-Grootenboer, A. R. M. M. Hermus, B. J. Otten, and M. A. Van't Hof, "Growth inhibition by glucocorticoid treatment in salt wasting 21-hydroxylase deficiency: in early infancy and (pre)puberty," Journal of Clinical Endocrinology and Metabolism, vol. 88, no. 8, pp. 3525-3530, 2003.

[30] H. J. Van der Kamp, B. J. Otten, N. Buitenweg et al., "Longitudinal analysis of growth and puberty in 21-hydroxylase deficiency patients," Archives of Disease in Childhood, vol. 87, no. 2, pp. 139-144, 2002.

[31] I. N. Silva, C. E. Kater, C. D. F. Cunha, and M. B. Viana, "Randomised controlled trial of growth effect of hydrocortisone in congenital adrenal hyperplasia," Archives of Disease in Childhood, vol. 77, no. 3, pp. 214-218, 1997.

[32] K. G. Saag, "Glucocorticoid-induced osteoporosis," Endocrinology and Metabolism Clinics of North America, vol. 32, no. 1, pp. 135-157, 2003.

[33] O. Arisaka, M. Hoshi, S. Kanazawa et al., "Effect of adrenal androgen and estrogen on bone maturation and bone mineral density," Metabolism, vol. 50, no. 4, pp. 377-379, 2001.

[34] J. S. Finkelstein, A. Klibanski, R. M. Neer et al., "Increases in bone density during treatment of men with idiopathic hypogonadotropic hypogonadism," Journal of Clinical Endocrinology and Metabolism, vol. 69, no. 4, pp. 776-783, 1989.

[35] J. R. Kerrigan, J. D. Veldhuis, S. A. Leyo, A. Iranmanesh, and A. D. Rogol, "Estimation of daily cortisol production and clearance rates in normal pubertal males by deconvolution analysis," Journal of Clinical Endocrinology and Metabolism, vol. 76, no. 6, pp. 1505-1510, 1993.

[36] B. L. Linder, N. V. Esteban, A. L. Yergey, J. C. Winterer, D. L. Loriaux, and F. Cassorla, "Cortisol production rate in childhood and adolescence," Journal of Pediatrics, vol. 117, no. 6, pp. 892-896, 1990.

[37] P. E. Clayton, S. E. Oberfield, E. Martin Ritzén et al., "Consensus: consensus statement on 21-hydroxylase deficiency from The Lawson Wilkins Pediatric Endocrine Society and the European Society for Pediatric Endocrinology," Journal of Clinical Endocrinology and Metabolism, vol. 87, no. 9, pp. 4048-4053, 2002.

[38] A. Morishima, M. M. Grumbach, E. R. Simpson, C. Fisher, and K. Qin, "Aromatase deficiency in male and female siblings caused by a novel mutation and the physiological role of estrogens," Journal of Clinical Endocrinology and Metabolism, vol. 80, no. 12, pp. 3689-3698, 1995.

[39] M. S. Cabrera, M. G. Vogiatzi, and M. I. New, "Long term outcome in adult males with classic congenital adrenal hyperplasia," Journal of Clinical Endocrinology and Metabolism, vol. 86, no. 7, pp. 3070-3078, 2001.

[40] N. M. M. L. Stikkelbroeck, B. J. Otten, A. Pasic et al., "High prevalence of testicular adrenal rest tumors, impaired spermatogenesis, and Leydig cell failure in adolescent and adult males with congenital adrenal hyperplasia," Journal of Clinical Endocrinology and Metabolism, vol. 86, no. 12, pp. 5721-5728, 2001. 
[41] A. D. Adinoff and J. R. Hollister, "Steroid-induced fractures and bone loss in patients with asthma," The New England Journal of Medicine, vol. 309, no. 5, pp. 265-268, 1983.

[42] B. A. Michel, D. A. Bloch, F. Wolfe, and J. F. Fries, "Fractures in rheumatoid arthritis: an evaluation of associated risk factors," Journal of Rheumatology, vol. 20, no. 10, pp. 1666-1669, 1993.

[43] T. P. Van Staa, R. F. Laan, I. P. Barton, S. Cohen, D. M. Reid, and C. Cooper, "Bone density threshold and other predictors of vertebral fracture in patients receiving oral glucocorticoid therapy," Arthritis and Rheumatism, vol. 48, no. 11, pp. 32243229, 2003.

[44] T. P. Van Staa, H. G. M. Leufkens, L. Abenhaim, B. Zhang, and C. Cooper, "Use of oral corticosteroids and risk of fractures," Journal of Bone and Mineral Research, vol. 15, no. 6, pp. 9931000, 2000.

[45] American College of Rheumatology Ad Hoc Committee on Glucocorticoid-Induced Osteoporosis, "Recommendations for the prevention and treatment of glucocorticoidinduced osteoporosis," Arthritis and Rheumatism, vol. 44, no. 7, pp. 1496-1503, 2001.

[46] E. Canalis, J. P. Bilezikian, A. Angeli, and A. Giustina, "Perspectives on glucocorticoid-induced osteoporosis," Bone, vol. 34, no. 4, pp. 593-598, 2004.

[47] E. Charmandari, S. M. Pincus, D. R. Matthews, A. Johnston, C. G. D. Brook, and P. C. Hindmarsh, "Oral hydrocortisone administration in children with classic 21-hydroxylase deficiency leads to more synchronous joint GH and cortisol secretion," Journal of Clinical Endocrinology and Metabolism, vol. 87, no. 5, pp. 2238-2244, 2002. 